\title{
An Investigation of the Relationship Between Shanghai Preschool Teachers' Developmentally Appropriate Beliefs and Practices
}

\author{
Bingjie Zou, ${ }^{1, *}$ \\ ${ }^{1}$ School of Primary Education, Shanghai Normal University Tianhua College, Shanghai, 201815, China \\ *Corresponding author. Email: zbj2073@sthu.edu.cn
}

\begin{abstract}
This quantitative study investigated the relationship between Shanghai preschool teachers' beliefs and their practices of Developmentally Appropriate Practice (DAP). Altogether 182 respondents from 13 preschools in Shanghai completed Teacher Beliefs and Practices Survey (three to five-year-olds) (including Teacher Beliefs Scale and Instructional Activities Scale) to report their DAP beliefs and practices in class. The results suggested a moderate positive relationship between teachers' beliefs and practices, implying that their practices tend to reflect their beliefs, but other factors may impede teachers from fully putting their beliefs into practice.
\end{abstract}

Keywords: teachers' beliefs, teachers ' practices, early childhood curriculum, DAP (Developmentally

Appropriate Practice)

\section{INTRODUCTION}

Teachers, as one of the important roles in the education process, hold individual beliefs not only about knowledge, teaching content and methods, but also about their students and themselves [1]. Interest in the study of teachers' beliefs started about 60 years ago. The premise of all studies on teachers' beliefs is that there is a relationship between teachers' belief system and their actual practice; as such, that the research on teachers' beliefs has implications for teaching quality and student achievement. Interestingly, while a number of studies reported a moderate consistency between teachers' beliefs and their practice [2],[3], there were also many studies reported a discrepancy between teachers' beliefs and teaching practice [4],[5].

Despite the inconsistency founded in many studies, there is "no reason to discount the power of beliefs" [2]. The discrepancy between teachers' beliefs and practice proves the complexity of the relationship and justifies the necessity to understand more about the belief-practice connection so as to better inform teachers, policymakers and teacher educators. It is even more crucial to understand teachers' beliefs and practice in the new era with a global trend of educational reform which calls for teachers to endorse new perceptions of teaching and adapt to new methods of teaching in practice [6].

The purpose of this study was to investigate the relationship between Shanghai preschool teachers' beliefs and their selfreported practice of developmentally appropriate practice (DAP). This study wanted to address the following research question: To what extent are teachers' beliefs about developmentally appropriate practice (DAP) and developmentally inappropriate practice (DIP) associated with their self-reported use of DAP and DIP?

\section{BACKGROUND}

It is of great value to study teachers' belief-practice relationship in Shanghai because it is one of the most developed and international cities in mainland China, and a leader in Chinese educational reform. Shanghai largely represents the effort to combine new educational conceptions and Chinese traditional ideas.

The early childhood education reform in China since late 1980s largely imported western-style theories and approaches such as constructivism, student-centered teaching approach and developmentally appropriate practice [7], promoting ideas like "respecting children, active learning, and play-based teaching and learning" [8]. As a pioneer city in China's educational reform, Shanghai issued an official preschool curriculum in 2004, reflecting many Western ideas and concepts. It defined the basic philosophy of early childhood education as childcenteredness, and argued that preschool curriculum should be appropriate for children's developmental stage. It also shows great emphasis on play-based learning, emphasized all-round development of children and required early childhood teachers to respect individual difference in their practice [9].

In these terms, the Shanghai preschool curriculum aligns much with developmentally appropriate practice (DAP), a constructivist, child-centered learning and teaching approach developed by the National Association for the Education of Young Children (NAEYC) in the United States, which refers to "applying child development 
knowledge in making thoughtful and appropriate decisions about early childhood program practices" and emphasizes age appropriateness, individual appropriateness and cultural appropriateness [10].

However, some previous studies done in China reported a "belief-practice gap" and a "policy-practice gap" [8]. Although most teachers accepted the ideas promoted by the curriculum reform in their self-reported beliefs, the actual practice of preschool classrooms of literacy instruction were still most frequently seen with teacher-directed whole-class instruction. The Chinese traditional value towards hardwork learning, the complexity of Chinese character learning, parents' expectation and demands, and limitation in resource may all be accounted for this gap.

The present study specifically investigated Shanghai preschool teachers' beliefs and practices of developmentally appropriate practice (DAP) in the large context of early childhood curriculum reform, to explore whether a western education philosophy can be successfully adapted to the Chinese context by understanding teachers' beliefs about the curriculum, and how their beliefs guide their implementation of the curriculum.

\section{METHOD}

\subsection{Participants}

A total of 182 full-time preschool teachers from 13 preschools in Shanghai participated in this study. Among these participants, nearly $96 \%$ were female teachers and nearly $60 \%$ were young teachers between 20 to 29 . About a half were new teachers with only 1-5 years of teaching experience and over one quarter were very experienced with more than 10 years of teaching experience. Nearly $70 \%$ hold bachelor's degree, and $13.7 \%$ had education beyond their bachelors' degree.

\subsection{Procedures}

The author randomly selected 13 preschools in a district in Shanghai and distributed the survey online to willing participants.

The participants did the Teacher Beliefs and Practices Survey (three to five-year-olds) and fill the demographic questionnaire individually through the websites set for the online survey. Both the survey and questionnaire were done anonymously, in order to protect participants' privacy and reduce the threat of subject effect to internal validity. The random sampling process recruited altogether 182 preschool teachers to complete the survey and provided with valid data. The response rate was $67.4 \%(182 / 270)$.

\subsection{Instruments}

The instrument used in this study is a Chinese version of the Teacher Beliefs and Practices Survey (three to five-yearolds) designed by Burts et al. [11]. The survey has two subscales: the Teacher Belief Scale (TBS) which measures teachers' beliefs, and the Instructional Activities Scale (IAS) which measures teachers' practice. Except the first ranking question in TBS, the Chinese version of TBS and IAS respectively contain 37 items and 34 items of 5-point Likert questions.

This instrument has strong evidence of reliability and validity. It is "the best known and most frequently used quantitative measures of early childhood teachers' beliefs and practice" in the United States [12]. Cronbach's alpha for TBS and IAS (Chinese version) were both 0.86 , including developmentally appropriate beliefs (.86), developmentally inappropriate beliefs (.81), developmentally appropriate activities (.84), and developmentally inappropriate activities (.8) [13].

A demographic questionnaire was used to collect information about the participants, including their gender, age, educational background, teaching experience, school type and class size.

\section{RESULTS}

Survey results reported that teachers in Shanghai kindergartens thought developmentally appropriate beliefs (DAB) as very important $(\mathrm{M}=3.88, \quad \mathrm{~s}=.69)$ and developmentally inappropriate beliefs DIB as less important, but still close to important $(\mathrm{M}=2.89, \mathrm{~s}=.60)$.

Teachers, according to the survey, claimed they practiced the appropriate practices " $2-4$ times a week" $(M=3.59, s=$ $.56)$, and the inappropriate practices were practiced less than "weekly," on average $(M=2.85, s=.69)$.

Pearson correlation analysis was then used to report the correlation coefficients of teachers' appropriate beliefs, inappropriate beliefs, appropriate activities, and inappropriate activities.

The author hypothesized that the extent to which Shanghai kindergarten teachers endorse the importance of appropriate beliefs (DAB) is positively correlated with self-reports of the frequency with which they engage in appropriate practices (DAP), and that the importance they place on inappropriate beliefs (DIB) is positively correlated with their use of inappropriate practices (DIP).

Table 1 shows a moderate correlation between teachers' appropriate beliefs and practices (Pearson $r=.557, p<.01$ ), according to the rule of thumb for interpreting correlations. Those who more strongly endorse the importance of appropriate beliefs also are those who more frequently engage in appropriate practices. Table 1 also shows a moderate correlation between teachers' inappropriate beliefs and practices (Pearson $r=.546, p<.01$ ). Similarly, this result meant that those who more strongly endorse the importance of inappropriate beliefs also are those who more frequently engage in inappropriate practices. 
In addition, Table 1 also showed "little if any correlation" between teachers' appropriate beliefs (DAB) and inappropriate practices (DIP), and teachers' inappropriate beliefs (DIB) and appropriate beliefs, according to the rule of thumb for interpreting correlations (Hinkle et. al., 2003, p.109).

Table 1. Correlations between teachers' beliefs and practice of DAP principles $(\mathrm{N}=182)$

\begin{tabular}{|l|l|l|}
\hline & $\begin{array}{l}\text { Appropriate } \\
\text { activities } \\
\text { (DAP) }\end{array}$ & $\begin{array}{l}\text { Inappropriate } \\
\text { activities } \\
\text { (DIP) }\end{array}$ \\
\hline $\begin{array}{l}\text { Appropriate } \\
\text { beliefs } \\
\text { (dab) }\end{array}$ & $.557^{* *}$ & $.209^{* *}$ \\
\hline $\begin{array}{l}\text { Inappropriate } \\
\text { beliefs } \\
\text { (dib) }\end{array}$ & $.268^{* *}$ & $.546^{* *}$ \\
\hline \multicolumn{2}{|r}{${ }^{* \mathrm{p}<.05 * \mathrm{p}^{*}<.01}$} \\
\hline
\end{tabular}

\section{DISCUSSION AND IMPLICATIONS}

This study examines the association between teachers' beliefs and practices. The results found a moderate positive correlation between teachers' appropriate beliefs and practices $(r=.557)$, and between teachers' inappropriate beliefs and practices $(r=.546)$. Teachers who more strongly endorse the appropriate beliefs tend to more frequently engage in appropriate practices, while teachers who more strongly endorse inappropriate beliefs more frequently implement inappropriate practices.

This result corroborates the findings of previous studies done both in other countries and China where similar moderate or low positive association between teachers' selfreported beliefs and practices were found [12],[13]. McMullen et al.'s comparison study reported a similar moderate correlation between teachers' beliefs and practices in the U.S. $(r=.68)$, Taiwan $(r=.61)$, Korea $(r=.47)$, and Turkey $(r=.47)$ [14]. Teachers' self-reported beliefs and practices are positively correlated suggesting some congruence in their beliefs and practices of DAP principles. However, the correlations are not high. The squared correlations show that beliefs account for about $30 \%$ of the variance in practice; still other factors may explain practice. Also, there may be other factors that moderate the beliefpractice relationship itself.

This study has several implications. First of all, teachers' belief systems concerning teaching and learning can be complex and can consist of different and even contradictory beliefs. As in this study, it is possible for a single teacher to have both appropriate and inappropriate beliefs. Secondly, teachers' beliefs are related with their practices, but what they believe does not necessarily equate to what they practice. This study reported a moderate positive correlation between teachers' beliefs and practices. Teachers' beliefs may have an influence on their practices, but teachers, especially new teachers, may have difficulty in putting what they learned and believe into practice. In actual practice, teachers may diverge from what they believe because of contextual factors, such as the reform requirements and class size, etc. Thirdly, application of the Developmentally Appropriate Beliefs (DAP) principles issued in the US may not all be directly suitable for the Chinese context of early childhood education. The study reported Shanghai kindergarten teachers have a certain extent of endorsement of inappropriate beliefs and frequency in engagement of inappropriate practices, but this inappropriateness is defined by the US DAP principles, which may be viewed differently according to traditional Chinese culture and values concerning education.

\section{CONCLUSION}

The positive belief-practice correlation reported in this study and previous research proves a necessity to understand teachers' beliefs because it indeed is an indicator of teachers' actual practices in classroom. However, the belief-practice correlation is only moderate suggests teachers' beliefs may have an influence on their practices, but teachers, especially new teachers, may have difficulty in putting what they learned and believe into practice. In actual practice, teachers may diverge from what they believe because of contextual factors, such as the reform requirements and class size, etc.

There is still more that can be done to strengthen the alignment between teachers' beliefs and practices. Teacher preparation and follow-up in-service training can be applied to strengthen the theories, concepts, and beliefs. In the context of curriculum reform in Shanghai, starting from educating teachers to assimilate the DAP beliefs and reconstruct their belief systems will make teachers more willing, on their own, to correspondingly adjust their practices rather than being forced to do so. In addition to education, the government, education authority and kindergartens need to try their best to provide teachers with support and favorable conditions to ensure teachers' practices are not restricted by contexts.

Further research can be done to investigate possible influencing factors of the belief-practice relationship. Observations within teachers' actual classrooms can be used to collect more accurate information about their practice in future investigations of the belief-practice relationship. Qualitative studies may be done to further explore teachers' beliefs of early childhood education, their understanding of the curriculum reform and their problems and difficulties in practices.

\section{REFERENCES}

[1] Levin, B. B. (2014). The development of teachers' beliefs. In Fives, H. \& Gill, M. G. (Eds.), International Handbook of Research on Teachers' Beliefs (pp. 4865). New York: Routledge. 
[2] Buehl, M. M., \& Beck, J. S. (2014). The relationship between teachers' beliefs and teachers' practice. In Fives, H. \& Gill, M. G. (Eds.), International Handbook of Research on Teachers' Beliefs (pp. 66-84). New York: Routledge.

[3] Lee, J. C., Zhang, Z., Song, H, \& Huang, X. (2013). Effects of Epistemological and Pedagogical Beliefs on the Instructional Practices of Teachers: A Chinese Perspective. Australian Journal of Teacher Education, 38(12), 120-146.

[4] Liu, S. H. (2011). Factors related to pedagogical beliefs of teachers and technology integration. Computers and Education, 56(4), 1012-1022.

[5] Wen, X., Elicker, J. G., \& McMullen, M. B. (2011). Early childhood teachers' curriculum beliefs: Are they consistent with observed classroom practices? Early Education \& Development, 22(6), 945-969.

[6] Yin, H. (2013). Implementing the national curriculum reform in China: A review of the decade. Front Education China, 8(3), 331-359.

[7] Pan, Y. J., \& Liu, Y. (2008). A comparison of curricular practices in Chinese kindergartens: The influences of curriculum reform. International Journal of Early Childhood, 40(2), 33-48.

[8] Li, H., Wang, X. C., \& Wong, J. M. S. (2011). Early childhood curriculum reform in China. Chinese Education \& Society, 44(6), 5-23.
[9] Shanghai Municipal Bureau of Statistics (2014). Shanghai Statistic Yearbook 2014. Retrieved from http://www.stats-sh.gov.cn/data/toTjnj.xhtml?y=2014e

[10] Copple, C. \& Bredekamp, S. (2009). Developmentally Appropriate Practice in Early Childhood Programs Serving Children from Birth through Age 8 ( ${ }^{\text {rrd }}$ ed.). Washington DC: National Association for the Education of Young Children.

[11] Burts, D.C., Buchanan, T.K., Charlesworth, R., \& Jambunathan, S. (2000). Rating scale for measuring the degree of developmentally appropriate practice in early childhood classrooms (3-5-year-olds). Baton Rouge, LA: Louisiana State University College of Education.

[12] Wang, J., Elicker, J., McMullen, M., \& Mao, S. (2008). Chinese and American preschool teachers' beliefs about early childhood curriculum. Early Child Development and Care, 178(3), 227-249.

[13] Hu, B. Y. (2012). Exploring the cultural relevance of developmentally appropriate practices from the point of view of preschool teachers in Beijing. CEDER Yearbook, 1-27.

[14] McMullen, M., Elicker, J., Wang, J., Erdiller, Z., Lee, S-M., Lin, C-H., \& Sun, P-Y. (2005). Comparing beliefs about appropriate practice among early childhood education and care professionals from the U.S., China, Taiwan, Korea, and Turkey. Early Childhood Research Quarterly, 20, 451-464. 